\title{
Other Education, Training, and Library Occupations
}

National Cancer Institute

\section{Source}

National Cancer Institute. Other Education, Training, and Library Occupations. NCI

Thesaurus. Code C122541.

Education, training, and library occupations not specifically identified elsewhere. 